\title{
Safety Assessment and Risk Management in Indian Building Construction Sites
}

\author{
S. Ajith C. Sivapragasam and V. Arumugaprabu
}

\begin{abstract}
Construction sites records high accident and incident rate due to lack of safety measures. Safety assessment rating is significant for every construction site to know safety status of the particular site. In this research $T R$ safety observation method is used to assess the site performance. As unsafe condition is the key factor in every construction site, this research considers the possible unsafe conditions to assess the site performance. A questionnaire survey is done with the workers to know the existing safe conditions. Results showed that the safety performance of the site is $39 \%$. Then every unsafe condition is ranked with respect to severity rating for detailed analysis. Furthermore bowtie analysis is used to identify the causes and consequences of the unsafe conditions. Through this analysis the owner can reduce the risk of every event and improve the site performance.
\end{abstract}

\section{Keywords : Construction, Unsafe condition, Safety, Performance}

\section{INTRODUCTION}

$\mathrm{C}$ onstruction sites consist of large number of workers involving in height work, hot work and heavy machineries. As workers in the construction sites are from different cultural background, language, experience and competency, these factors might lead to the risks for workers in construction sites [1,2]. Risk management is a key factor to minimize the injuries and accidents in construction sites. It includes hazard identification, assessment and suggesting suitable mitigation measures [3]. The two major contributory factors for accidents are unsafe acts and unsafe conditions. It is said that nearly $80 \%$ of the accidents are due to unsafe acts of the workers in the site [4] but still it is the duty of the organization to look into unsafe conditions to reduce the $20 \%$ of the accidents and to make construction site into a risk free zone. Safety can't be enhanced only by considering the previously occurred accidents because the sites have different nature of work and work environment.

Revised Manuscript Received on December 05, 2019.

Mr. S. Ajith, research scholar at Kalasalingam Academy of Research and Education, India.

Dr. C.Sivapragasam ,PhD from NUS, Singapore.

Dr. V. Arumugaprabu PhD from Kalasalingam Academy of Research and Education, India.
Hence the eengineer's should look over each and every accident, its causes and propose suitable mitigation measures to make the site as accident free zone [5]. Construction companies seek for new approaches to reduce work related accidents as the sites records higher number of fatal and non-fatal accidents. The traditional approach is well-organized safety training. It can reduce frequent accidents but still it has many challenges as learning and experience of the workers [6].

The safety performance level can be determined using TR safety index method. TR is derived from the Finnish words that denote the meaning of building construction. This method is a simple standardized method for site observation. In this approach a checklist is made in which if the particular activity satisfies the safety standard, it was scored as correct and the others are scored as not correct. The percentage of the correct score denotes the safety index.

TR Index = Agree/(Agree+Disagree ) x $100 \quad$ [7,8]

The combination of both the fault tree and event tree analysis is known as bowtie. Fault tree represents the accidents and its causes whereas event tree represents the accidents and its consequences. When both the trees are combined a bowtie is formed [9]. Bowtie is a representation of causes and consequences of hazards which is also a hazard analysis technique. There are two different types of bowties such as qualitative and quantitative. Qualitative bowties are the simplest representation of cause and effect of an event whereas the quantitative bowties represents the risk values [10]

Safety Management (SM) plays a key role in implementing the required safety systems, maintaining the quality, establishing the modern safety climate, evaluating the performance and reviewing the existing systems. These are done to minimize the accident - incident rate and to ensure the safety of workers $[11,12]$.

From the previous literatures it is noted that most of the studies focused on unsafe behavior of the workers. But the factors behind every accident are unsafe acts of the workers and unsafe conditions of the site. As Unsafe Conditions (UC) contributes to the accidents, this research focuses on unsafe conditions of the workplace in order to make construction site as risk free zone

The main objectives of this research are as follows

- To evaluate the site performance using TR safety index.

- To determine the cause and consequences of unsafe conditions. 


\section{ASSESSMENT OF SITE PERFORMANCE}

\section{A. Questionnaire survey}

A questionnaire survey is conducted with the workers in the building construction site to know about the existing safety conditions. All the unsafe conditions that can lead to serious consequences in the construction sites are listed in the questionnaire as mentioned in Table I. Only two options are given for each questions indicating whether the conditions exists or not. As workers involve in each and every activity they are chosen as respondents.

Table I Questionnaire survey for site assessment

\begin{tabular}{|c|c|c|}
\hline S.No & Unsafe Conditions & Reference \\
\hline 1. & Barricading the excavation & {$[13]$} \\
\hline 2. & Pathway for carrying reinforcement & [14] \\
\hline 3. & $\begin{array}{l}\text { Storing paint waste away from the } \\
\text { premises }\end{array}$ & [14] \\
\hline 4. & $\begin{array}{l}\text { Separate place for stacking the } \\
\text { materials }\end{array}$ & [14] \\
\hline 5. & Certification of cranes & [14] \\
\hline 6. & Proper PPE for welding & [15] \\
\hline 7. & Warning lights in scaffold & [16] \\
\hline 8. & Maintenance of floors & [17] \\
\hline 9. & Maintenance of vehicles & [18] \\
\hline 10. & Inspection of hoist & [18] \\
\hline 11. & PPE for Drilling & Adopted in this research \\
\hline 12. & Shed for bar bending & Adopted in this research \\
\hline
\end{tabular}

\section{B. Determining the severity of unsafe conditions}

Severity rate is known as the consequence of a particular event or condition. It is determined by the nature of injury as mentioned in Table II. The severity rate for each unsafe condition is obtained through the constructional safety experts.

Table II Severity rate

\begin{tabular}{cll}
\hline Severity Rate & Terms & Description \\
\hline 1 & Negligible & Improbability of injuries \\
2 & Minor & Impermanent discomfort \\
3 & Moderate & Deafness, burns and sprains \\
4 & Major & Serious injuries \\
5 & Catastrophic & Fatality \\
\hline
\end{tabular}

\section{Assessment of site performance using TR safety} index

The questionnaire survey is analysed as mentioned in Table III and TR safety index equation is used to determine the site performance. It is noted that only $39 \%$ of the site conditions are safer (i.e., those conditions satisfies the safety norms). The remaining $61 \%$ fails to fulfil the safety norms and it is considered as unsafe. In order to overcome this, the owner has to modify or change the unsafe conditions as mentioned in safety standards to make it safer.

Table III List of sub task regarding unsafe condition

\begin{tabular}{llll}
\hline S.No & TASK & AGREE & DISAGREE \\
\hline 1. & $\mathrm{UC}_{1}$ & 116 & 0 \\
2. & $\mathrm{UC}_{2}$ & 17 & 96 \\
3. & $\mathrm{UC}_{3}$ & 7 & 109 \\
4. & $\mathrm{UC}_{4}$ & 86 & 30 \\
5. & $\mathrm{UC}_{5}$ & 77 & 36 \\
6. & $\mathrm{UC}_{6}$ & 97 & 16 \\
7. & $\mathrm{UC}_{7}$ & 18 & 98 \\
8. & $\mathrm{UC}_{8}$ & 39 & 76 \\
9. & $\mathrm{UC}_{9}$ & 22 & 93 \\
10. & $\mathrm{UC}_{10}$ & 26 & 88 \\
\hline
\end{tabular}

\section{Ranking of unsafe conditions}

Severity rate for each unsafe condition is determined and ranking is done as shown in Table IV. Then the unsafe condition which has high severity rate is analysed using qualitative bowtie method to find the causes and consequences of an unwanted event.

Table IV Severity rate and ranking of unsafe conditions

\begin{tabular}{|c|c|c|c|c|}
\hline S.No & $\begin{array}{l}\text { List of } \\
\text { Conditions } \\
\end{array}$ & Unsafe & Severity Rate & Rank \\
\hline 1. & $\mathrm{UC}_{1}$ & & 4 & 1 \\
\hline 2. & $\mathrm{UC}_{2}$ & & 3 & 4 \\
\hline 3. & $\mathrm{UC}_{3}$ & & 1 & 7 \\
\hline 4. & $\mathrm{UC}_{4}$ & & 1 & 7 \\
\hline 5. & $\mathrm{UC}_{5}$ & & 1 & 7 \\
\hline 6. & $\mathrm{UC}_{6}$ & & 4 & 1 \\
\hline 7. & $\mathrm{UC}_{7}$ & & 1 & 7 \\
\hline 8. & $\mathrm{UC}_{8}$ & & 2 & 5 \\
\hline 9. & $\mathrm{UC}_{9}$ & & 1 & 7 \\
\hline 10. & $\mathrm{UC}_{10}$ & & 1 & 7 \\
\hline 11. & $\mathrm{UC}_{11}$ & & 4 & 1 \\
\hline 12. & $\mathrm{UC}_{12}$ & & 2 & 5 \\
\hline
\end{tabular}

\section{E. Hazard Analysis Using Bowtie}

The bowtie diagram is a systematic representation used to establish the cause and consequences of an unsafe condition as shown in Fig.1. There are four major steps involved in a bowtie diagram. They are identifying the top event (i.e., hazardous event which exist in the site), list the maximum causes for the top event to occur, list the consequences of each causes and mitigation measures. The maximum possible causes and its consequences for a particular unsafe condition are shown in Fig.2, Fig.3 and Fig.4. It represents the causes and consequences for accidents in excavation, hot work and drilling. Hence by identifying the possible causes, the Safety Engineers should review the previous accidents and compare it with the present accident. From the comparison it is known that whether the accident occurred due to the listed causes or else from the new cause. It is also suggested that the builders/owners should implement the safety systems as prescribed by national safety codes. Furthermore through bowtie analysis the causes for accidents can be mitigated by establishing safety \& risk management to make the activity as risk free zone.

\section{EVALUATION OF CONTROL MEASURES}

The proactive measures as suggested through the bowtie are discussed with a panel of safety experts and are implemented in the particular site to reduce the percentage of risk. A check list is prepared by listing the UC as mentioned in the questionnaire survey and walk around audit is done. Check list is a systematic evaluation of established criteria. Through the check list method of evaluation it is known that the level of agreement has been increased to a higher percentage as mentioned in Fig.5, this indicates that the percentage of risk and the number of UC have been reduced. If these mitigation measures are adopted and followed, the risk in construction site will reduce considerably. 


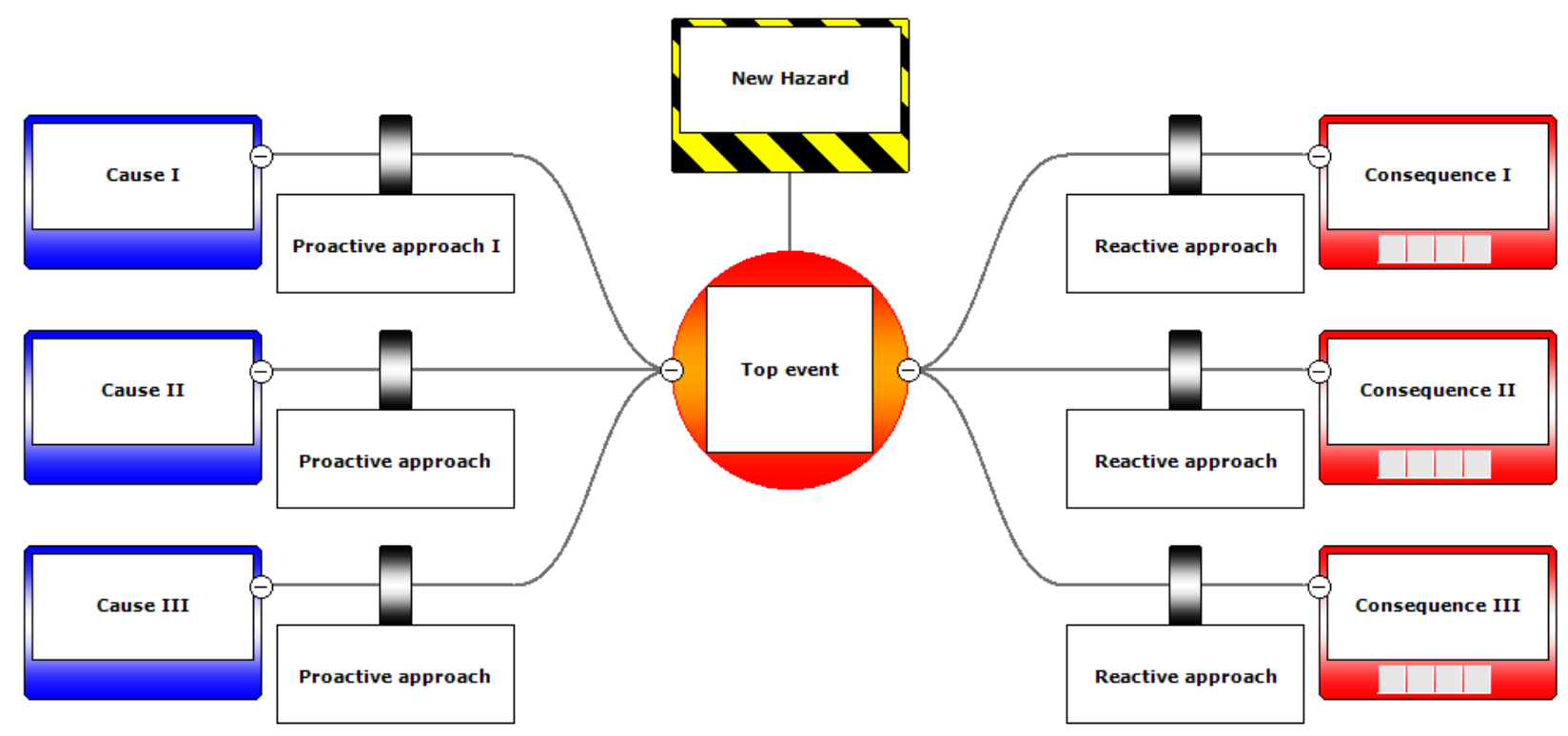

Fig.1 Generalized Bowtie

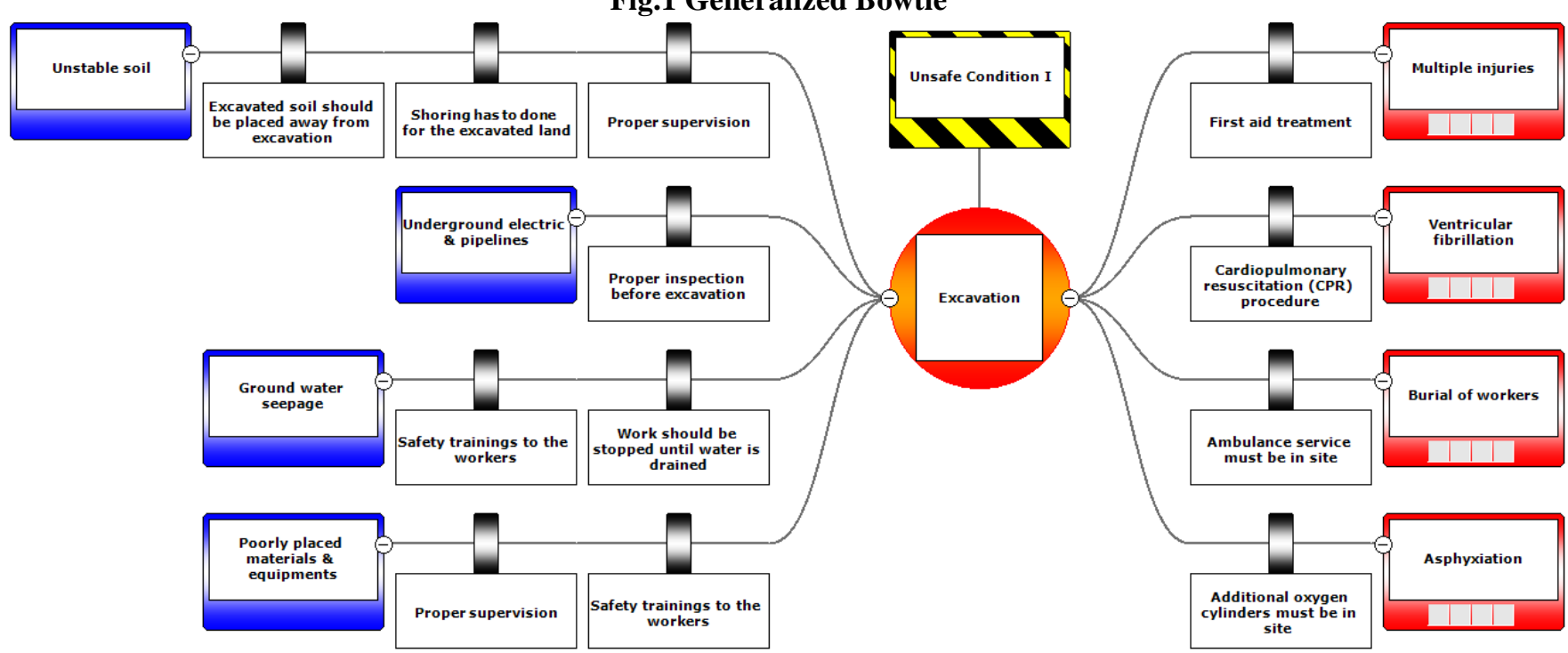

Fig. 2 Bowtie for excavation

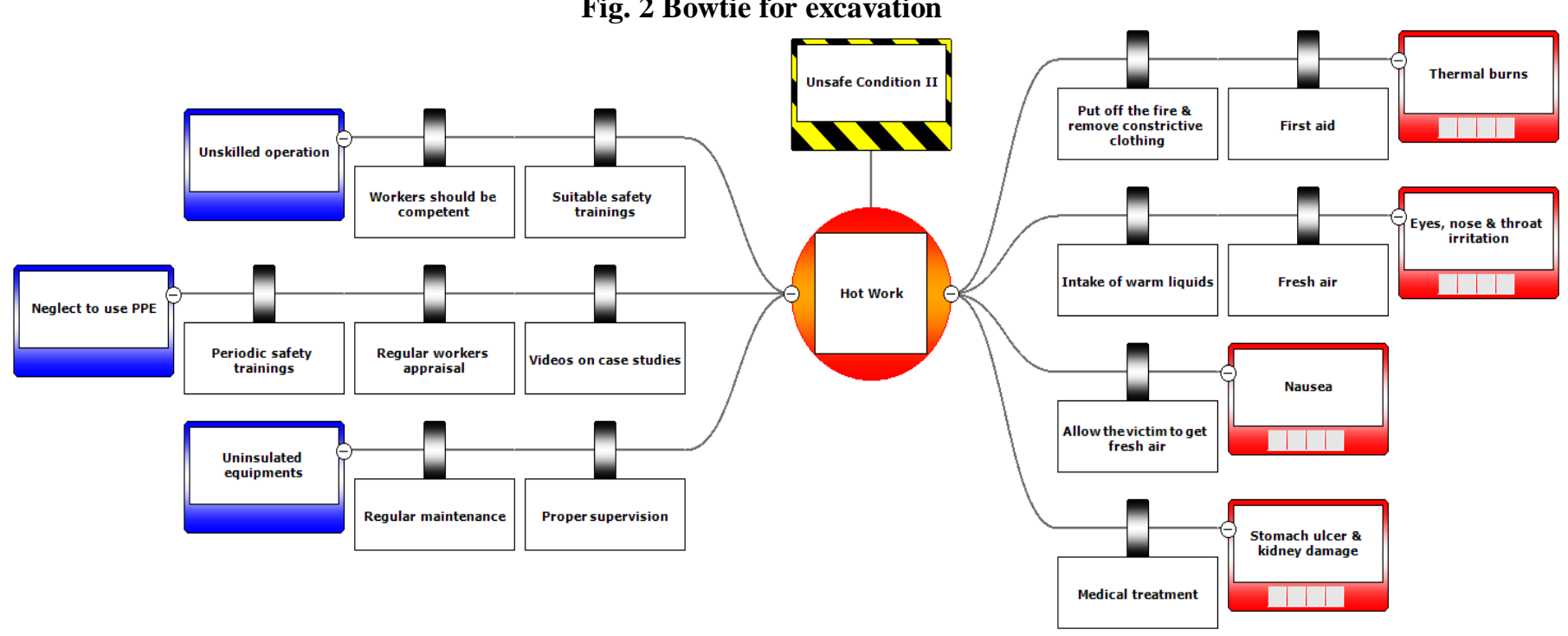

Fig. 3 Bowtie for hot work

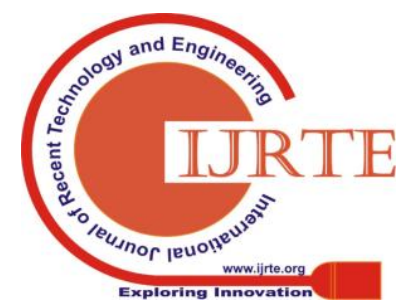




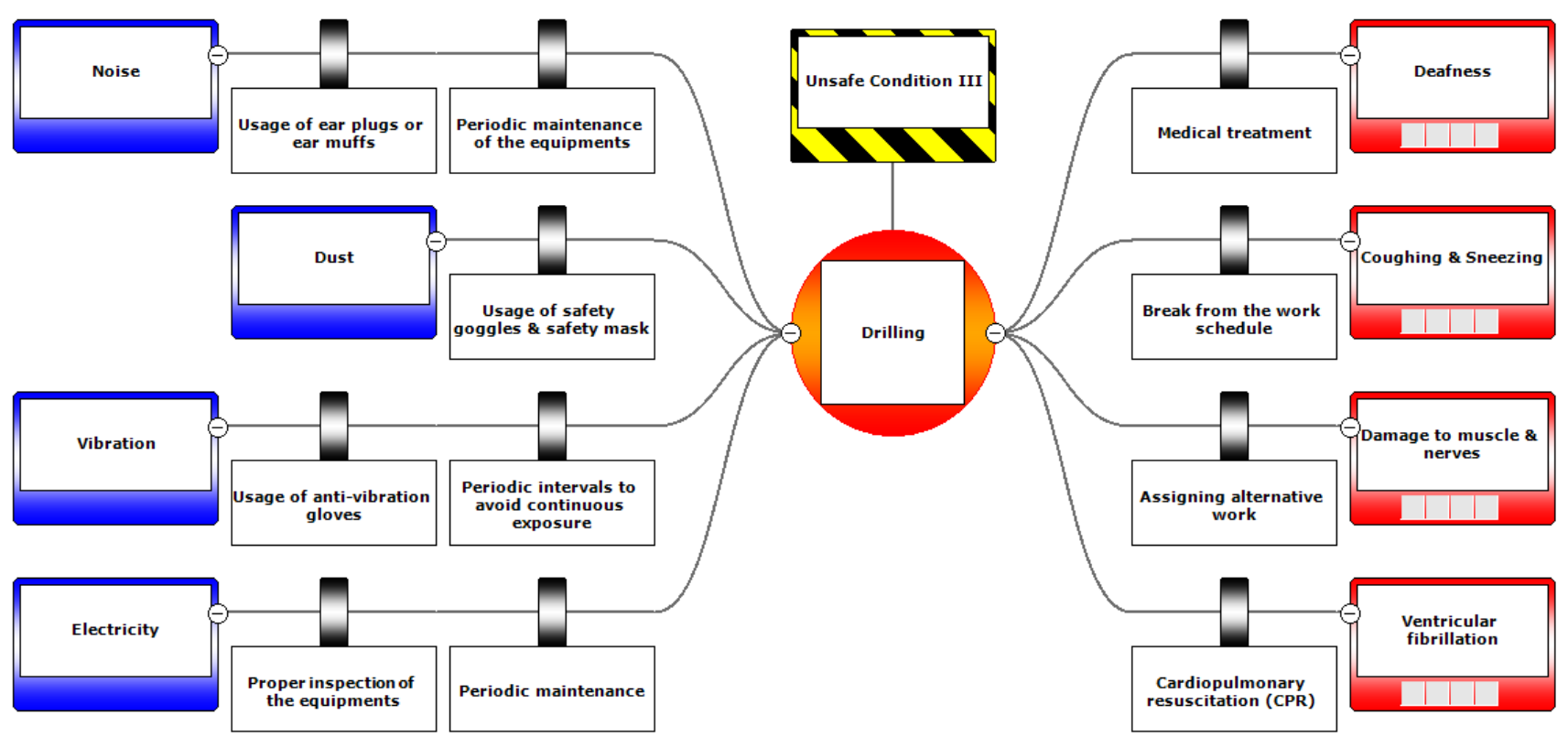

Fig. 4 Bowtie for drilling

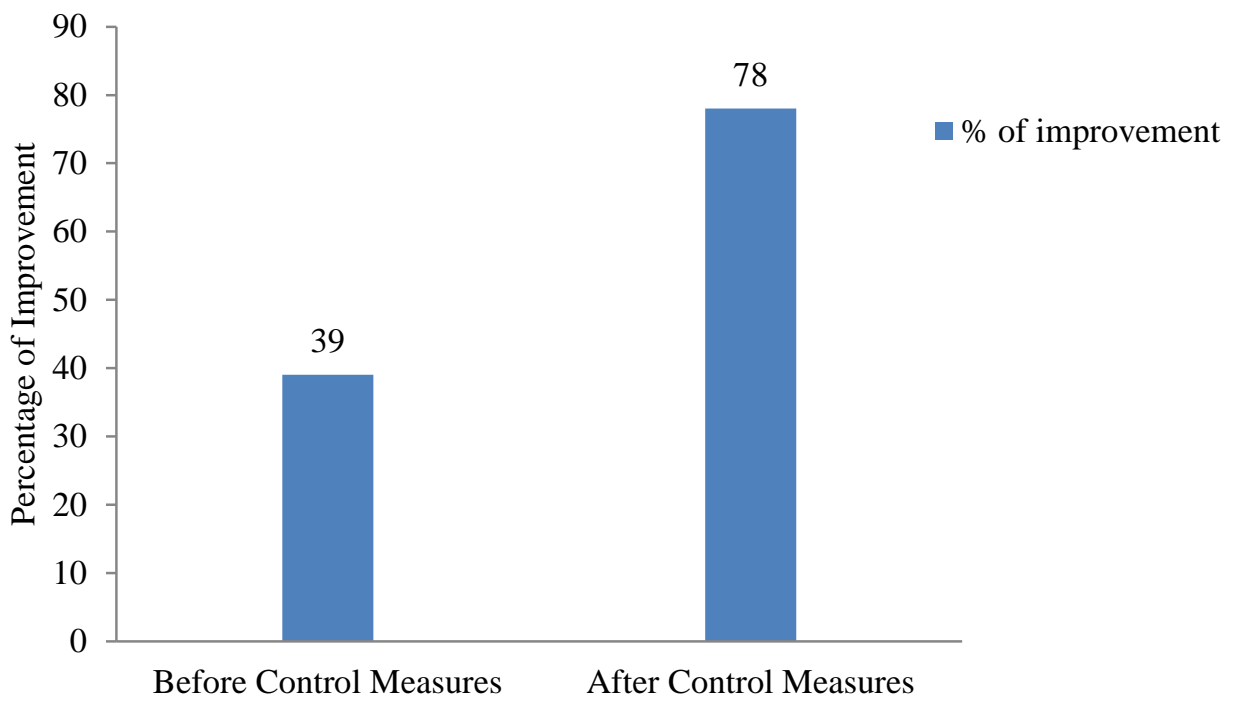

Fig. 5 Evaluation of control measures

\section{CONCLUSIONS}

The following conclusions are drawn from this research

- From the performance assessment it is known that only $39 \%$ of the site is safer. Hence it is suggested that the management should look over the unsafe conditions in the site to satisfy the requirements as prescribed in the safety standards. $20 \%$ of the accident rate can be reduced by establishing safe working conditions.

- Bowtie method is adopted in order to identify the causes and consequences of the unsafe conditions. This method is used to minimize the existing hazards and prevent further hazards in the site.

\section{REFERENCES}

1. R. Gao, A. P. Chan, S. Lyu, H. Zahoor, \& W. P. Utama, "Investigating the difficulties of implementing safety practices in international construction projects". Safety science, 108, 2018, pp. 39-47.

2. E. W. Cheng, N. Ryan, \& S. Kelly, "Exploring the perceived influence of safety management practices on project performance in the construction industry”. Safety Science, 50(2), 2012, pp. 363-369.

3. M. Kraus, "Risk assessments of contemporary accidents in construction industry". EDP Sciences, In MATEC web of conferences, Vol. 146, 2018, pp. 03004.

4. R. M. Choudhry \& D. Fang "Why operatives engage in unsafe work behavior: Investigating factors on construction sites". Safety science, 46(4), 2008, pp. $566-584$. 
5. F. J. Forteza, A. Sese, \& J.M Carretero-Gómez, CONSRAT. "Construction sites risk assessment tool". Safety science, 89, 2016, pp. 338-354.

6. S. Demirkesen \& D. Arditi, "Construction safety personnel's perceptions of safety training practices". International Journal of Project Management, 33(5), 2015, pp. 1160-1169.

7. M. Gunduz \& H. Laitinen, "Observation based safety performance indexing method for construction industry-validation with SMEs". KSCE Journal of Civil Engineering, 22(2), 2018, pp. 440-446.

8. H. Laitinen, M. Marjamäki \& K. Päivärinta, "The validity of the TR safety observation method on building construction". Accident Analysis \& Prevention, 31(5), 1999, pp. 463-472.

9. A. De Ruijter \& F. Guldenmund, "The bowtie method: A review". Safety science, 88, 2016, pp. 211-218.

10. B. J. M. Ale, H. Baksteen, L. J. Bellamy, A. Bloemhof, L. Goossens, A. Hale \& J.Y. Whiston, "Quantifying occupational risk: The development of an occupational risk model". Safety science, 46(2), 2008, pp. 176-185.

11. X. Wu, Q. Liu, L. Zhang, M. J. Skibniewski \& Y. Wang, "Prospective safety performance evaluation on construction sites". Accident Analysis \& Prevention, 78, 2015, pp. 58-72.

12. M. Gunduz \& B. Ahsan, "Construction safety factors assessment through frequency adjusted importance index". International Journal of Industrial Ergonomics, 64, 2018, pp. 155-162.

13. Indian Standard 3764:1992 (Reaffirmed 1996). Excavation Work Code of Safety.

14. Indian Standard 7969: 1975 (Reaffirmed 2002). Safety Code of Handling and Storage of Building Materials.

15. Indian Standard 7205:1974 (Reaffirmed 2006) Safety code for Erection of Structural Steel Work.

16. Indian Standard 3696 (Part I): 1987 (Reaffirmed 2002) Safety Codes for Scaffolds and Ladders.

17. Tamil Nadu Factories Rules 1950.

18. Tamil Nadu Building and Other Construction Workers (Regulation of Employment and Condition of Services) Rules 2006.

\section{AUTHORS PROFILE}

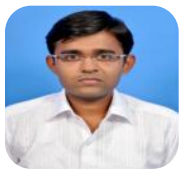

Mr. S. Ajith has completed his graduation and post-graduation from KTVR Knowledge Park for Engineering \& Technology and University Departments of Anna University respectively. Currently he is a research scholar at Kalasalingam

Academy of Research and Education, India.

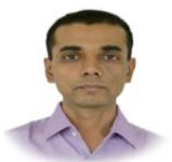

Dr. C.Sivapragasam has completed his graduation and post-graduation from IIT-Roorkee and IIT-Delhi respectively. He completed his $\mathrm{PhD}$ from NUS, Singapore. He has 2 years of industry experience and more than 17 years of teaching experience. He has completed 3 sponsored research projects from various funding agencies and published more than 70 papers in peer reviewed journals and conferences.

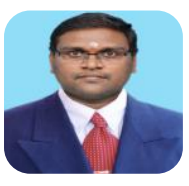

Dr. V. Arumugaprabu has completed his graduation in Mechanical Engineering and post-graduation in CAD/CAM from Arulmigu Kalasalingam College of Engineering and Mepco Schlenk Engineering College respectively. He completed his $\mathrm{PhD}$ from Kalasalingam Academy of Research and Education, India. He has 12 years of teaching experience. He has completed 1 sponsored research project from funding agencies and published more than 80 papers in peer reviewed journals and conferences. 